\title{
Displasia renal em cães: estudo retrospectivo (2008-2013)
}

\author{
Renal Dysplasia in Dogs: Retrospective Study (2008-2013)
}

\section{Samara Rosolem Lima' ${ }^{1}$ Leilane Aparecida da Silva ${ }^{1}$, Geovanny Bruno Gonçalves Dias', Letícya Lerner Lopes', Raquel Aparecida Sales da Cruz², Luciana Sonne², Caroline Argenta Pescador' \& Edson Moleta Colodel'}

\begin{abstract}
Background: Renal dysplasia, which has been reported in some dogs and human patients, refers to a developmental disorder of renal parenchyma due to imperfect inductive interaction between the mesonephric duct and the metanephric blastemal. In dogs, the characteristic histological findings on which diagnosis is based include (1) persistent metanephric ducts surrounded by primitive mesenchyme, (2) fetal or immature glomeruli, (3) fetal or immature tubules, and (4) anomalous presence of interstitial fibrous tissue. The aim of this study was to report the major pathological and immunohistochemical features of nine young dogs necropsied with renal dysplasia.

Cases: The necropsy files from the Laboratório de Patologia Veterinária (LPV) of the Universidade Federal do Mato Grosso (UFMT) were reviewed between the years 2008 and 2013. Dogs diagnosed with chronic kidney failure and macroscopic and histopathological renal lesions consistent with renal dysplasia were selected. Kidney fragments in paraffin blocks were cut and stained with hematoxylin and eosin and by immunohistochemistry (IHC) using anti-vimentin and anti-cytokeratin monoclonal antibodies. The staining was considered positive for the presence of at least one renal cell marked with brown cytoplasmic staining clear and unambiguous. A total of 787 necropsies of dogs were performed. Of these, 64 had a clinical diagnosis of chronic renal failure of which 9 were classified as renal dysplasia. The age of the dogs ranged from 3 months to 2 years. Clinical signs were characterized by anorexia and non-regenerative anemia in $88.9 \%$, vomiting $66.7 \%$, dehydration $55.6 \%$, uremia $55.6 \%$, convulsion $33.4 \%$, abdominal pain $22.3 \%$ and diarrhea in $11.2 \%$ of cases. At necropsy the main macroscopic changes in the kidneys were external surface with pale staining, in 6 of 9 dogs necropsied. Additionally, 5 dogs, cystic cavities of various sizes from 0.1 to $5 \mathrm{~cm}$ in diameter, diffusely distributed in the renal subcapsular surface and cutting were observed. Of the 64 dogs with diagnosis of chronic renal failure, $14.06 \%$ had dysplastic kidney changes, characterized by dilatation of Bowman's space, glomerular and tubular atrophy, immature glomeruli and tubules, lymphocytic interstitial inflammation and fibrosis. In the dogs with renal dysplasia, it was observed that the tubular structures showed marked glomerular labeling for vimentin. Moreover, the kidneys of normal dogs showed weak or absent for marking tubes and glomerular structures for vimentin, and strong staining for cytokeratin in tubular cells, glomerular cells and collecting ducts.

Discussion: Renal morphological damage observed in these nine dogs less than two years old, that contained degenerative and inflammatory changes, fibrosis and glomerular atrophy, but mostly immature glomeruli and tubules were associated with atypical renal dysplasia. This condition develops when the urethral diverticulum and metanephric blastoma not properly form in the embryonic stage, resulting in abnormal metanephric differentiation and formation of structures that do not recapitulate the normal nephrogenesis. Abnormal kidney function in young animals caused chronic renal failure resulting in death. The results of immunohistochemical observed in this study can complement the diagnosis of renal dysplasia. The morphological normality can be observed in the proportion of mesenchymal and epithelial tissue in the different structures of the kidney by staining with anti-cytokeratin and anti-vimentin. In the present study, there was moderate to strong labeling of vimentin in glomerular and tubular structures being dysplastic kidney would be expected to occur in normal dogs predominant staining with cytokeratin. Based on the clinic, pathological and immunohistochemical findings it is concluded that the animals developed renal dysplasia.
\end{abstract}

Keywords: juvenile nephropathy, renal failure, nephrogenesis, immunohistochemistry.

Descritores: nefropatia juvenil, insuficiência renal, nefrogênese, imunohistoquímica. 


\section{INTRODUÇÃO}

Nefropatia juvenil (NPJ) designa um grupo de doenças renais progressivas [4], congênita ou hereditária, que acomete animais jovens [10] e causa sinais clínicos relacionados à insuficiência renal crônica [14].

As alterações morfológicas renais classificam os casos de NPJ em: glomerulopatia juvenil (primária ou imunomediada), rim policístico, amiloidose, síndrome de Fanconi e displasia renal [5]. Dentre estas, a displasia renal é a mais comum sendo caracterizada pelo desenvolvimento embrionário desorganizado do parênquima e estroma renal [10].

Em cães a nefrogênese é incompleta, ocorrendo maturação tecidual até 10 semanas após nascimento. Entretanto, na displasia renal as estruturas imaturas persistem devido ao desequilíbrio na interação entre o blastoma metanéfrico e divertículo uretral, prejudicando a transformação do tecido mesenquimal em epitelial [13]. Em cães os mecanismos que levam a esta malformação ainda são obscuros, sendo a obstrução uretral intra-uterina, agentes teratogênicos e a infecção neonatal por herpesvírus canino as principais causas apontadas $[10,12]$. O objetivo do trabalho é relatar as principais características clínicas, epidemiológicas, patológicas e imuno-histoquímicas de 09 cães com displasia renal necropsiados no Laboratório de Patologia Veterinária (LPV) da Universidade Federal de Mato Grosso (UFMT) no período de janeiro de 2008 a dezembro de 2013.

\section{CASOS}

Foram realizadas, no período de janeiro de 2008 a dezembro de 2013, necropsias de 9 de cães com diagnóstico clínico de IRC e lesões renais macroscópicas e histológicas compatíveis com displasia renal [5]. Fragmentos de diversos órgãos em parafina incluindo o rim foram recortados e corados pela técnica de hematoxilina e eosina (HE) [3].

A idade dos cães variou de três meses a dois anos, sendo sete $(77,8 \%)$ fêmeas e dois $(22,2 \%)$ machos. Em relação à raça, três $(33,3 \%)$ eram pit bull, dois $(22,2 \%)$ labradores, dois $(22,2 \%)$ sem raça definida (SRD), um $(11,1 \%)$ fila brasileiro e um $(11,1 \%)$ Beagle. Os sinais clínicos relatados foram caracterizados por anorexia e anemia não regenerativa em $88,9 \%$ (8/9), vômito 66,7\% (6/9), desidratação 55,6\% (5/9), uremia 55,6\% (5/9), convulsão 33,4\% (3/9), dor abdominal $22,3 \%$ (2/9) e diarreia em $11,2 \%$ (1/9) dos casos. Dos nove cães necropsiados, oito $(88,9 \%)$ tiveram morte espontânea e um $(11,1 \%)$ foi eutanasiado. $\mathrm{Na}$ necropsia as principais alterações macroscópicas foram localizados nos rins sendo caracterizados por superfície subcapsular de coloração pálida, em 6/9 cães necropsiados. Adicionalmente, em cinco cães, foram observadas cavidades císticas (Figura 1A) de tamanhos variados, de 0,1 a $5 \mathrm{~cm}$ de diâmetro, difusamente distribuídas na superfície subcapsular e de corte renal. Ao corte, outros achados incluíram, superfície irregular e pontos esbranquiçados, de aproximadamente $0,1 \mathrm{~mm}$ de diâmetro, de distribuição multifocal no parênquima renal em quatro cães, áreas císticas na região cortical em três cães, estrias esbranquiçadas de aproximadamente 0,1 a 0,3 $\mathrm{mm}$ de diâmetro na junção córtico-medular em oito cães e em um cão foi observado dilatação da pelve renal.

Os achados microscópicos mais relevantes foram localizados nos túbulos renais, sendo caracterizados pela presença de túbulos imaturos (Figura 1B) contendo células cubóides ou colunares com citoplasma escasso, em todos os nove cães. Outros achados incluíram dilatação tubular e áreas de deposição de material amorfo basofílico irregular (mineralização) ao redor e no interior dos túbulos em sete cães. Nos glomérulos, os nove casos apresentavam dilatação da cápsula de Bowman (Figura 1C) e, em seis, a ocorrência de estruturas glomerulares imaturas (Figura 1D). Adicionalmente, material amorfo hialino, associado à mineralização, foi observado no interior e ao redor de glomérulos em seis cães e atrofia dos tufos glomerulares em quatro cães. Em sete cães havia extensas áreas com proliferação de fibroblastos no tecido intersticial. Infiltrado inflamatório linfoplasmocitário multifocal também foi notado em sete cães e áreas de mineralização intersticial foram constatadas em dois cães.

A Imunohistoquímica (IHQ) foi empregada utilizando anticorpos monoclonais anti-citoqueratina ${ }^{1}$ (Dako) na diluição de 1:100 e anti-vimentina ${ }^{1}$ (Dako) na diluição de 1:100 em fragmentos de rim sendo a recuperação antigênica realizada mediante a solução de tampão citrato $\mathrm{pH}$ 6,0 atingindo uma temperatura de $90^{\circ} \mathrm{C}$ por $10 \mathrm{~min}$. O sistema de detecção aplicado foi o complexo biotina-streptavidina-peroxidase ${ }^{1}$. O cromógeno utilizado foi a diaminobenzidina ${ }^{1}$ (DAB). Como controles positivos foram utilizados carcinoma de células escamosas para citoqueratina e melanoma para vimentina. A positividade para vimentina e 
citoqueratina foi determinada pela presença de pelo menos uma célula renal marcada com coloração citoplasmática marrom nítida e inequívoca sendo a marcação determinada pelo método semi-quantitativo. O método semi-quantitativo foi baseado na soma da proporção de coloração das células renais mesenquimais, glomerulares/tubulares e células ductos coletores. O número de células positivas de cada corte foi estipulado em escores sendo - negativo; + menos de $10 \%$ das células positivas; $++11-50 \%$ das células positivas; +++ mais de $50 \%$ das células positivas. Rins de cães com idades similares e sem alteração morfológica e foram utilizados como comparativo para histoquímica e IHQ.

$\mathrm{Na}$ análise IHQ, a caracterização da displasia foi notada por alterações evidenciadas em três componentes: glomérulos/estruturas tubulares primitivas, túbulos relembrando ductos coletores e mesenquima. Nos nove cães com displasia renal, foi observado que as estruturas tubulares, glomerulares, assim como a estrutura de sustentação das células dos glomérulos, vasos sanguíneos e células intersticiais apresentaram acentuada marcação para vimentina. Adicionalmente, os túbulos relembrando ductos coletores foram marcados com citoqueratina que também marcou intensamente na região medular, as estruturas dos ductos coletores e alça de Henle, enquanto que na região cortical esta marcação foi fraca e ou ausente. Por outro lado, os rins de cães normais apresentaram marcação para vimentina fraca ou ausente em estruturas tubulares e glomerulares e marcação forte para citoqueratina nas células tubulares, glomerulares e nas células dos ductos coletores. Um resumo da marcação imunohistoquímica encontra-se na Tabela 1.

Tabela 1. Comparação dos resultados imuno-histoquímicos observados em cães com displasia renal e cães normais.

\begin{tabular}{|c|c|c|c|c|c|c|}
\hline \multirow[t]{2}{*}{ Imunohistoquímica } & \multicolumn{3}{|c|}{ Cães com displasia } & \multicolumn{3}{|c|}{ Cães controles (normais) } \\
\hline & $\mathrm{CM}$ & CGT & $\mathrm{CDC}$ & $\mathrm{CM}$ & CGT & $\mathrm{CDC}$ \\
\hline Vimentina & +++ & +++ & + & + & + & - \\
\hline Citoqueratina & - & - & ++ & - & +++ & +++ \\
\hline
\end{tabular}

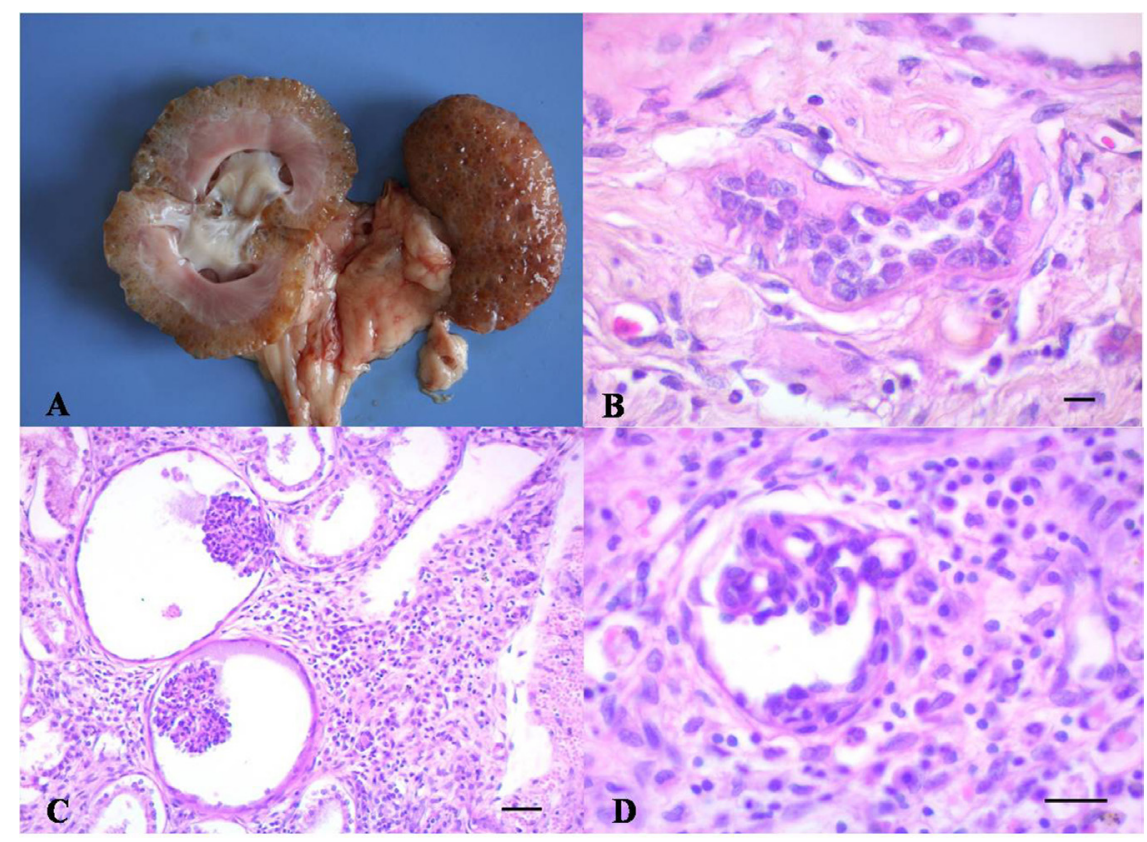

Figura 1. Cão. Displasia renal. Rim. A. Superfície subcapsular: irregular, pálida e contendo múltiplos cistos. Superfície de corte: Múltiplas formações císticas no córtex e dilatação da pelve renal moderada. B. Túbulos primitivos circundados por epitélio hipercromático e fibrose intersticial (HE, Obj.63x). [Barra= 5 micras]. C. Atrofia do tufo glomerular e dilatação da cápsula de bowman. Infiltrado linfoplasmocitário focal moderado, HE, Obj. 20x. [Barra = 20 micras]. D. Glomérulo imaturo (HE, obj. 63x). [Barra = 100 micras]. 


\section{DISCUSSÃO}

As lesões morfológicas renais caracterizadas por alterações degenerativas, inflamatórias, atrofia glomerular e formação de túbulos e glomérulos imaturos, foram, nestes 9 cães, associados à displasia renal [1].

Cães que apresentam esse distúrbio no desenvolvimento embrionário dos rins podem manifestar uma variabilidade de sinais clínicos sistêmicos $[4,7]$. No presente estudo, os sinais clínicos registrados com maior frequência foram anorexia, anemia e vômito sendo associados à doença renal em estágio avançado [4].

$\mathrm{Na}$ avaliação macroscópica dos rins, os principais achados foram similares aos descritos na literatura [14]. Microscopicamente, a hipertrofia e hiperplasia compensatória dos tufos glomerulares e túbulos são inespecíficos e podem ocorrer em outras doenças renais com função renal comprometida [6]. Além disso, as alterações degenerativas e inflamatórias, na maioria das vezes mascaram a lesão morfológica de displasia, e, portanto, devem ser observadas com cuidado para não serem erroneamente interpretadas, comprometendo o diagnóstico da causa primária de IRC [12]. Embora alguns autores relatem a formação atípica de epitélio tubular como lesão primária de displasia renal [12], nesse estudo essa alteração microscópica não foi observada. Essas lesões ocorrem em cães idosos com lesão renal de causa inespecífica e também são similares às observadas em ovinos acidentalmente ou experimentalmente intoxicados por cloreto de cálcio anidro [8] sugerindo que a presença deste epitélio adenomatóide representa em caninos, um mecanismo compensatório secundário de proliferação celular dos ductos coletores como uma tentativa de aumentar a secreção de íons de hidrogênio na acidose metabólica urêmica, portanto, não sendo considerada essencial para confirmar a displasia renal.

Os resultados da imuno-histoquímica observados no presente trabalho complementam o diagnóstico de displasia renal [11]. A normalidade morfológica pode ser observada em relação à proporção de tecido epitelial e mesenquimal nas diferentes estruturas do rim através da marcação com anticorpos anti-citoqueratina e anti-vimentina [11]. No presente estudo, ocorreu marcação moderada a forte pela vimentina nas estruturas tubulares e glomerulares de rins displásicos sendo que seria esperado em cães normais que ocorresse predomínio de marcação com citoqueratina. Entretanto, deve-se ter cuidado na interpretação dos resultados, uma vez que células tubulares renais podem também marcar com vimentina em outras condições patológicas [9]. Adicionalmente, um padrão diferenciado de marcação glomerular também pode ser visualizado dependendo do tipo de citoqueratina utilizada $[9,11]$.

Com base nos dados clínico-patológicos e imunohistoquímicos foi possível diagnosticar o quadro de displasia renal nos 9 cães estudados.

\section{MANUFACTURER}

${ }^{1}$ Dako North America Inc. Carpinteria, CA, USA.

Acknowledgments. Ao MEC pela bolsa concedida através do programa de Residência Uniprofissional em Medicina Veterinária.

Declaration of interest. The authors report no conflicts of interest. The authors alone are responsible for the content and writing of the paper.

\section{REFERENCES}

1 Azizi S., Kheirandish R. \& Yazdanpour H. 2010. Histopathologic features of a unilateral renal dysplasia in a cat (Felis domestica). Comparative Clinic Pathology. 19: 445-447.

2 Basile A., Onetti-Muda A., Giannakakis K., Faraggiana T. \& Aresu L. 2011. Juvenile Nephropathy in a boxer dog resembling the human nephronophthis - Medullary cystic kidney disease complex. The Journal of Veterinary Medical Science. 73(12): 1669-1675.

3 Behmer O.A., Tolosa R.M.C \& Freitas Neto A.G. 1976. Manual de Técnicas para Histologia Normal e Patológica. São Paulo: EDART, p.239.

4 Chandler M.L., Elwood C., Murphy K.F., Gajanayake I. \& Syme H.M. 2007. Juvenile nephropathy in 37 boxer dogs. Journal os Small Animal Pratice. 48: 690-694.

5 Elliott J. \& Grauer F.G. 2007. BSAVA Manual of canine and feline Nephrology and Urology. 2nd edn. Gloucester: BSAVA, 252p.

6 Gopegui R.R., Espada Y., Ortuno A. \& Fondevila D. 2001. Nefropatia congênita em Schnauzer miniatura. Clínica Veterinária de pequenos animais. 21(4): 328-332. 
7 Hunning P.S., Aguiar J., Lacerda L.A., Sonne L., Oliveira E.C. \& Haas G.F. 2009. Displasia renal em um cão. Acta Scientiae Veterinariae. 37(1): 73-77.

8 Jansen J.H. \& Arnesen K. 1990. Oxalate nephropathy in a Tibetan Spaniel litter. A probable of primary hyperoxaluria. Journal of Comparative Pathology. 103(1): 79-84.

9 Kawate T., Kawamura R., Uchida T., Takahashi K., Hasegawa T., Futamata H., Katoh R. \& Takeda S. 2009. Histochemical Analysis of Renal Dysplasia with Ureteral Atresia. Acta Histochemica et Cytochemica. 42(3):65-71.

10 Maxie M.G. \& Newman S. 2007. Urinay system. In: Jubb K.V.F., Kennedy P.C. \& Palmer N. (Eds). Pathology of domestic animals. v.2. 5th edn. Philadelphia: Saunders Elsevier, pp.447-538.

11 Moll R., Hage C. \& Thoenes W. 1991. Expression of intermediate filamento proteins in fetal and adult human kidneys: modulations of intermediate filamento patterns during development and in damaged tissue. Laboratory Investigation. 65(1): 74-86.

12 Picut C.A. \& Lewis R.M. 1987. Microscopic features of canine renal dysplasia. Veterinary Pathology. 24(2): 156-163.

13 Rojas C.P., Urbiztondo A.K., Bruce J.H. \& Rodriguez M. 2011. Comparative immunohistochemical study of multicystic dysplastic kidneys with and without obstruction. Fetal Pedriatric Patologhy. 30(4): 209-2019.

14 Tabacchi L., Chavera A.C., Perales C.R., Sandoval N.C. Santillán G.A., Palacios C.E. \& Malca S.O. 2004. Primer reporte de nefropatía juvenil (Displasia renal) en una Golden Retriever. Revista de Investigacions Veterinárias do Perú. 15(2): 179-184. 